\title{
ASOCIATION OF URINARY TRACT INFECTION AND PNEUMONIA AMONG PATIENTS WITH ISCHEMIC STROKE AT A TERTIARY CARE HOSPITAL.
}

\author{
DR. JAVERIA SHAMIM
}

MBBS

NISHTAR HOSPITAL, MULTAN, PAKISTAN.

\section{DR. RABIA SHAUKAT}

MBBS

NISHTAR HOSPITAL, MULTAN, PAKISTAN.

\section{DR. IQRA SALEEM}

MBBS

NISHTAR HOSPITAL, MULTAN, PAKISTAN.

\begin{abstract}
;
Objective; To determine the association of urinary tract infections and pneumonia among patients with ischemic stroke at a tertiary care hospital. Material and Methods; All the cases of ischemic stroke (181), fulfilling inclusion criteria were recruited in this cross - sectional study. Once registered these study cases was assessed for different complications (UTI, shoulder pain, arrhythmia, pneumonia and hyponatremia) after undergoing baseline investigations like urine test, blood tests and ECG. Data was entered and analyzed by computer program SPSS-18. Results; Of these 181 study cases, 101 (55.8\%) were male patients while $80(44.2 \%)$ were female patients. Mean age of our study cases was $50.68 \pm 7.18$ years. Of these 181 study cases, $80(44.2 \%)$ were from rural area while 101 (55.8\%) from urban areas, $43(23.8 \%)$ were diabetic and $118(65.2 \%)$ were hypertensive. Mean body mass index (BMI) of our study cases was $23.58 \pm 3.29 \mathrm{~kg} / \mathrm{m}^{2}$ and obesity was present in $29(16 \%)$. History of smoking was present in $43(23.8 \%)$ of our study cases. Previous history of stroke was present in 21 $(11.6 \%)$ while family history of stroke was noted in $37(20.4 \%)$ of our study cases and $130(71.8 \%)$ were illiterate and $51(28.2 \%)$ were literate. Mean serum sodium level was noted to $136.29 \pm 2.01 \mathrm{mEq} / \mathrm{L}$, urinary tract infection (UTI) was noted in $87(48.1 \%)$, shoulder pain in $72(39.8 \%)$, pneumonia in $43(23.8 \%)$, arrhythmia in $58(32 \%)$ and hyponatremia in $51(28.2 \%)$ of our study cases. Conclusion; Our study results indicate high proportion of medical complications in patients with ischemic stroke. Urinary tract infection was the most commonest complication followed by shoulder pain, arrhythmia, pneumonia and hyponatremia. All clinicians treating such patients should carefully monitor such patients to take preventive measure against these complications, this will decrease disease morbidity and hospitalizations in these patients.
\end{abstract}

Keywords; Ischemic stroke, medical complications, Frequency.

DOI: $10.7176 / \mathrm{JMPB} / 58-02$

Publication date: August $31^{\text {st }} 2019$

\section{INTRODUCTION;}

Stroke, a global health problem, is a leading cause of death and disability throughout the world ${ }^{1}$. The results of stroke are not only persistent neurologic deficits but also marked deconditioning ${ }^{2}$. Stroke patients constitute the largest group of patients who require rehabilitation services. During the rehabilitation process, patients are vulnerable to various complications as a result of both the stroke and the disability caused by it ${ }^{3}$. Ischemic 
Stroke occurs as a result of an obstruction within a blood vessel supplying blood to the brain. It accounts for 60 90\% percent of all stroke cases in Pakistan. The risk factors for stroke are classified as non-modifiable (age, family history, prior stroke, gender and ethnicity) and modifiable risk factors (hypertension, diabetes mellitus, coronary artery disease, arterial fibrillation, dyslipidemia, smoking, obesity, alcohol abuse and physical inactivity ${ }^{4-6}$.

Diagnosis and treatment of stroke have advanced over the past 2 decades, but morbidity and mortality after stroke are still high. Patients who have had stroke are at significant risk for medical complications, neurological damage, and various psychiatric illnesses ${ }^{7}$. Even if not always life-threatening, these medical complications can hinder functional recovery, can extend the hospital length of stay, worsen stroke outcomes and increase cost of care. In addition, some patients need to be transferred back to the acute care setting, which interrupts the inpatient rehabilitation therapy and further increases the overall cost of stroke management ${ }^{8}$. Civelek et al ${ }^{9}$ reported UTI in $48.1 \%$ patients, shoulder pain in $37 \%$, arrhythmia in $21 \%$ and pneumonia in $13.6 \%$ of ischemic stroke patients. Rodrigues et al ${ }^{10}$ reported $16 \%$ hyponatremia in patients having ischemic stroke.

\section{MATERIAL AND METHODS;}

A total of 181 patients with ischemic stroke were included in this study having their ages ranging from $25-65$ years were included. Patients with hemorrhagic stroke, metabolic encephalopathy meningitis, arrhythmia before onset of ischemic stroke and history of brain tumors before onset of symptoms of stroke were excluded from our study. All the cases of ischemic stroke fulfilling inclusion criteria were recruited from Department of Medicine, Nishtar Hospital, Multan. Once registered these study cases was assessed for different morbidity pattern (UTI, shoulder pain, arrhythmia, pneumonia and hyponatremia as defined in operational definitions) after undergoing baseline investigations like urine test, blood tests and ECG. Data was entered and analyzed by computer program SPSS-18.

\section{RESULTS;}

Our study comprised of 181 patients with ischemic stroke who met inclusion criteria of our study. Of these 181 study cases, $101(55.8 \%)$ were male patients while $80(44.2 \%)$ were female patients. Mean age of our study cases was $50.68 \pm 7.18$ years (with minimum age of our study cases was 30 years while maximum age was 60 years). Mean age of the male patients was $53.51 \pm 5.10$ years while that of female patients was $48.44 \pm 7.79$ years $(\mathrm{p}=0.000)$. Our study results have revealed that majority of our patients i.e. $102(56.4 \%)$ were aged more than 45 years. Of these 181 study cases, $80(44.2 \%)$ were from rural area while $101(55.8 \%)$ from urban areas, $43(23.8 \%)$ were diabetic and $118(65.2 \%)$ were hypertensive. Mean body mass index (BMI) of our study cases was $23.58 \pm 3.29 \mathrm{~kg} / \mathrm{m}^{2}$ and obesity was present in $29(16 \%)$. History of smoking was present in $43(23.8 \%)$ of our study cases. Mean disease duration of our study cases was $4.18 \pm 1.22$ months and $99(54.7 \%)$ had disease duration more than 3 months and history of alcohol consumption was zero. Previous history of stroke was present in $21(11.6 \%)$ while family history of stroke was noted in $37(20.4 \%)$ of our study cases and $130(71.8$ $\%)$ were illiterate and $51(28.2 \%)$ were literate. Mean serum sodium level was noted to $136.29 \pm 2.01 \mathrm{mEq} / \mathrm{L}$, urinary tract infection (UTI) was noted in $87(48.1 \%)$, shoulder pain in $72(39.8 \%)$, pneumonia in $43(23.8 \%)$, arrhythmia in $58(32 \%)$ and hyponatremia in $51(28.2 \%)$ of our study cases.

\section{DISCUSSION;}

Stroke syndromes present clinically as neurologic deficits of sudden onset. Symptoms depend upon the affected region of brain, which in turn is defined by the arterial anatomy involved ${ }^{11}$. Our study comprised of 181 patients with ischemic stroke who met inclusion criteria of our study. Of these 181 study cases, 101 (55.8\%) were male patients while $80(44.2 \%)$ were female patients. Different studies have documented male gender preponderance in patients with ischemic stroke. A study conducted by Saeed et al ${ }^{12}$ also reported high male gender predominance with $61.1 \%$ in patients with ischemic stroke which is similar to our findings. Javed et al ${ }^{13}$ from Dera Gazi Khan also reported $61 \%$ male patients showing male gender predominance which is same as that of our study results. Similarly Farooq et al ${ }^{14}$ from Faisalabad has documented $54 \%$ male patients with ischemic stroke which is in compliance with our study results. Sico et al ${ }^{15}$ also reported $58 \%$ male gender preponderance which is similar to our study results.

Mean age of our study cases was $50.68 \pm 7.18$ years (with minimum age of our study cases was 30 years while maximum age was 60 years). Mean age of the male patients was $53.51 \pm 5.10$ years while that of female patients was $48.44 \pm 7.79$ years $(\mathrm{p}=0.000)$. Our study results have revealed that majority of our patients i.e. $102(56.4 \%)$ were aged more than 45 years. A study conducted by Saeed et al ${ }^{12}$ also reported $64.4 \pm 11.5$ years mean age 
which is slightly higher than that of the findings of our study. Khan et al ${ }^{16}$ reported $58.11 \pm 15.29$ years mean age which is close to our study results. Soyama et al ${ }^{17}$ from Japan also reported that mean age of men was 2.6 years higher than that of women. Our study results have documented similar findings which are in compliance with Soyama et $\mathrm{al}^{17}$. Abid et al ${ }^{18}$ reported $55.96 \pm 13.75$ years mean age of the patients presenting with ischemic stroke which is similar to that of our study results. Of these 181 study cases, $80(44.2 \%)$ were from rural area while 101 (55.8\%) from urban areas, $43(23.8 \%)$ were diabetic and 118 (65.2\%) were hypertensive. Mean body mass index (BMI) of our study cases was $23.58 \pm 3.29 \mathrm{~kg} / \mathrm{m}^{2}$ and obesity was present in $29(16 \%)$. History of smoking was present in $43(23.8 \%)$ of our study cases. Sadreddini et al ${ }^{19}$ also reported from Iran that patients with ischemic stroke presented with diabetes in $24 \%$ patients, hypertension in $78 \%$ patients and smoking in 20 $\%$. Our results are in compliance with that of Sadreddini et al ${ }^{19}$ from Iran. Khan et al ${ }^{16}$ also reported diabetes in $36.6 \%$ and smoking in $32 \%$ patients with ischemic stroke. These results are similar to that of our study results.

Mean disease duration of our study cases was $4.18 \pm 1.22$ months and 99 (54.7\%) had disease duration more than 3 months and history of alcohol consumption was zero. Previous history of stroke was present in 21 $(11.6 \%)$ while family history of stroke was noted in $37(20.4 \%)$ of our study cases and $130(71.8 \%)$ were illiterate and $51(28.2 \%)$ were literate. Sadreddini et al ${ }^{19}$ from Iran reported $18 \%$ previous history of stroke which is close to our study results. Mean serum sodium level was noted to $136.29 \pm 2.01 \mathrm{mEq} / \mathrm{L}$, urinary tract infection (UTI) was noted in $87(48.1 \%)$, shoulder pain in $72(39.8 \%)$, pneumonia in $43(23.8 \%)$, arrhythmia in $58(32 \%)$ and hyponatremia in $51(28.2 \%)$ of our study cases. Civelek et al ${ }^{9}$ reported UTI in $48.1 \%$ patients, shoulder pain in $37 \%$, arrhythmia in $21 \%$ and pneumonia in $13.6 \%$ of ischemic stroke patients, these findings are close to our study findings. Rodrigues et al ${ }^{10}$ reported $16 \%$ hyponatremia in patients having ischemic stroke which is in compliance with our findings.

\section{CONCLUSION}

Our study results indicate high proportion of medical complications in patients with ischemic stroke. Urinary tract infection was the most commonest complication followed by shoulder pain, arrhythmia, pneumonia and hyponatremia. All clinicians treating such patients should carefully monitor such patients to take preventive measure against these complications, this will decrease disease morbidity and hospitalizations in these patients.

\section{REFERENCES}

1. Kim KJ, Heo M, Chun IA, Jun HJ, Lee JS, Jegal H, et al. The relationship between stroke and quality of life in Korean adults: based on the 2010 Korean community health survey. J Physicians Ther Sci. 2015,27:309-12.

2. Kim K, Kim YM, Kim EK. Correlation between the activities of daily living of stroke patients in a community setting and their quality of life. J Physicians Ther Sci. 2014;26:417-19.

3. Doshi VS, Say JH, Young SH, Doraisamy P. Complications in stroke patients: a study carried out at the Rehabilitation Medicine Service, Changi General Hospital. Singapore Med J. 2003,44:643-52.

4. Feigin VL. Stroke in developing countries: can the epidemic be stopped and outcomes improved? Lancet Neurol. 2007;6(2):94-7.

5. Okokhere PO, Bankole IA, Erohubie CA. Characteristics, risk factors and case fatality rate of stroke in hospitalized patients in semi-urban South Nigeria. SAGE Open Med. 2013;1: 2050312113516112. doi:10.1177/2050312113516112.

6. Zahra F, Kidwai SS, Siddiqi SA, Khan RM. Frequency of newly diagnosed diabetes mellitus in acute ischaemic stroke patients. J Coll Physician Surg Pak. 2012;22(4):226-9.

7. Wang JY1, Wang CY, Tan CH, Chao TT, Huang YS, Lee CC. Effect of different antipsychotic drugs on short-term mortality in stroke patients. Medicine (Baltimore). 2014 Nov;93(25):e170. doi: 10.1097/MD.0000000000000170.

8. Hung JW, Tsay TH, Chang HW, Leong CP, Lau YC. Incidence and risk factors of medical complications during inpatient stroke rehabilitation. Chang Gung Med J. 2005;28(1):31-8.

9. Civelek GM1, Atalay A2, Turhan N3. Medical complications experienced by first-time ischemic stroke patients during inpatient, tertiary level stroke rehabilitation. J Physicians Ther Sci. 2016 Jan;28(2):38291. 
10. Rodrigues B, Staff I, Fortunato G, McCullough LD. Hyponatremia in the prognosis of acute ischemic stroke. J Stroke Cerebrovasc Dis. 2014;23(5):850-4.

11. Mutch CA1, Talbott JF2, Gean A3. Imaging Evaluation of Acute Traumatic Brain Injury. Neurosurg Clin N Am. 2016 Oct;27(4):409-39.

12. Saeed E, Ali R, Jalal-ud-din M, Saeed A, Jadoon RJ, Moiz M. Hypercholesterolemia in patients of ischemic stroke. J Ayub Med Coll Abbottabad. 2015 Jul-Sep;27(3):637-9.

13. Javid RA, Bhatti A, Azhar MA. Frequency of hypoalbuminemia in patients with ischemic stroke. Pak J Med Health Sci. 2016;10(2):571-73.

14. Farooq MA, Anjum MS, Malik FA, Kalsoom N. Frequency of microalbuminuria in patients with ischemic stroke. Rawal Med J. 2013;38(2):97-99.

15. Sico JJ1, Concato J, Wells CK, Lo AC, Nadeau SE, Williams LS, et al. Anemia is associated with poor outcomes in patients with less severe ischemic stroke. J Stroke Cerebrovasc Dis. 2013 Apr;22(3):271-8.

16. Khan MN, Khan HD, Ahmad M, Umair M. Serum total and HDL-cholesterol in ischemic and hemorrhagic stroke. Ann Pak Inst Med Sci 2014;10(1)22-26.

17. Soyama Y1, Miura K, Morikawa Y, Nishijo M, Nakanishi Y, Naruse Y, et al. High-density lipoprotein cholesterol and risk of stroke in Japanese men and women: the Oyabe Study. Stroke. 2003 Apr;34(4):863-8.

18. Abid N, Khan SA, Taseer IH. Frequency of hyperlipidemia in patients presenting with ischemic stroke. Pak J Med Health Sci. 2012;6(2):423-28.

19. Sadreddini SA, Abolfathi AA, Khandaghi R, Talebi M, Lakian A. C-Reactive protein, fibrinogen, LP (a), lipid profile levels and platelet count in patients with ischemic stroke. Pak J Neurological Sci. 2006;1(1):7-13. 